\title{
MIDAS
}

Museus e estudos interdisciplinares

$3 \mid 2014$

Varia e dossier temático: "Museos y participación biográfica"

\section{Museus do feminino, museologia de género e o contributo da história}

Women's museums, gender museology and the contribution of history

\section{Irene Vaquinhas}

\section{(2) OpenEdition}

\section{Journals}

\section{Edição electrónica}

URL: http://journals.openedition.org/midas/603

DOI: $10.4000 /$ midas.603

ISSN: 2182-9543

\section{Editora:}

Alice Semedo, Paulo Simões Rodrigues, Pedro Casaleiro, Raquel Henriques da Silva, Ana Carvalho

\section{Refêrencia eletrónica}

Irene Vaquinhas, « Museus do feminino, museologia de género e o contributo da história », MIDAS

[Online], 3 | 2014, posto online no dia 08 junho 2014, consultado no dia 30 abril 2019. URL : http:// journals.openedition.org/midas/603; DOI : 10.4000/midas.603

\section{Este documento foi criado de forma automática no dia 30 Abril 2019}

\section{cc) (†)}

Midas is licensed under a Creative Commons Attribution-NonCommercial-ShareAlike 3.0 International License 


\section{Museus do feminino, museologia de género e o contributo da história}

Women's museums, gender museology and the contribution of history

Irene Vaquinhas

\section{Introdução: algumas definições e objetivos visados pela museologia de género}

1 Este artigo tem como objetivo principal tecer algumas considerações sobre a articulação entre a história das mulheres e os museus. Trata-se de um tema fraturante, pouco consensual e que suscita vários tipos de leituras e de reações críticas, senão mesmo sorrisos irónicos, chegando-se a associar os museus da mulher a exposições de sutiãs e de roupa interior...

Críticas à parte, são muitos os autores que questionam a legitimidade da fundação de museus das mulheres e de género ${ }^{1}$, bem como a aplicação de perspetivas de género à museologia atual, ou seja, que se considere a condição feminina como eixo estruturante das coleções, permanentes ou temporárias, de museus e das atividades desenvolvidas no espaço museal ${ }^{2}$. A museologia de género subentende também a feminização das funções de direção e de curadoria de museus ou de instituições museológicas ${ }^{3}$, a qual é considerada indispensável à concretização de políticas de boas práticas.

O conceito de museologia de género é relativamente recente, tendo surgido nos anos 1990. Resultou da convergência de diferentes fatores, provenientes tanto da área específica da museologia como do campo dos estudos das mulheres e do género. Pode-se evocar a este propósito, no primeiro caso, a emergência da nova museologia, a qual apela ao papel social e inclusivo dos museus, valências que vêm na sequência de decisões expressas na Carta de Santiago do Chile de 1972 e na Declaração de Quebeque de 1984. Trata-se de textos fundadores que, por um lado, instituem o museu integral, «ao serviço da sociedade», e, por outro, vinculam os museus a novas funções sociais (Rodriguez 2010, 13), como agentes de comunicação e de intervenção social, tendo como epicentro o 
indivíduo e a comunidade, deixando o museu de ser encarado como mero local de armazenamento de coleções ou de memórias.

4 Já no que concerne aos estudos das mulheres e do género destacam-se, entre outros fatores, o impulso dado pelos movimentos feministas ao estudo de um passado coletivo de ostracismo e, no tocante à ciência histórica propriamente dita, o desenvolvimento de novas áreas de pesquisa, que resultaram, em parte, de uma reação à ignorância, ao injusto esquecimento, senão mesmo a uma apreciação sistematicamente negativa da história das mulheres (Vaquinhas 2005b, 125-127), bem como o deslocamento do objeto da pesquisa histórica dos acontecimentos de natureza política para os da vida privada e quotidiana (Vaquinhas 2011a, 164-166), o que favoreceu o aparecimento de novas problemáticas centradas na construção social dos papéis sexuais.

5 A museologia de género resulta, por conseguinte, da convergência destas novas áreas de estudo e apresenta-se como um discurso crítico sobre o papel social e político dos museus na sociedade contemporânea, procurando, sobretudo, resgatar a memória e os patrimónios femininos e dar visibilidade à participação ativa das mulheres na vida social, política, cultural e quotidiana, tanto no passado como no presente. Visa igualmente valorizar as expressões culturais e artísticas femininas, prestar reconhecimento a todas as mulheres que, ao longo do tempo, constituíram coleções, bem como a todas aquelas que, através do exercício de práticas museológicas, impulsionaram a organização de fundos.

6 Tornar visível o protagonismo feminino aos níveis museal e patrimonial é também entendido como um ato de justiça e um passo em frente na construção de uma sociedade mais justa, que aplica os conceitos de igualdade de género, de inclusão social e de democracia participativa (Rechena 2011, 239). Por outras palavras, a museologia de género não é neutral e contém uma dimensão interventiva que valoriza a equidade social e a luta contra estereótipos dando visibilidade às mulheres e às suas realizações.

7 Trata-se, no entanto, de um campo de saber de escassa aplicação prática e sub-teorizada em termos de reflexão epistemológica, sobretudo se confrontada com outras áreas científicas, nos quais os estudos das mulheres e de género têm tido grande desenvolvimento, como é o caso, entre outras, da antropologia, dos estudos literários e linguísticos ou mesmo da história.

8 Nos inícios dos anos 1990, quando esta problemática começou a ser equacionada, a revista Museum, da UNESCO, consagrou-lhe um número monográfico intitulado Museus no Feminino (1991, n. 3). A coordenadora, a dinamarquesa Skjoth, no editorial que então redigiu, embora reconhecesse o ocultamento do feminino nos museus, questionava a utilidade da abertura de museus das mulheres (1991, 124-125). Levantava, no entanto, algumas questões, cujas respostas, em seu entender, podiam conduzir a um equilíbrio de género e a novas estratégias no espaço museal, mais precisamente as seguintes: que imagens das mulheres transmitem as exposições? Que atividades são reservadas ao sexo feminino que trabalham nos museus e como podem ser melhoradas as perspetivas de carreira? Como é que os museus podem contribuir para melhorar a condição feminina? Provindos de vários cantos do mundo, os pareceres emitidos foram, de uma forma geral, positivos.

9 No que respeita ao nosso país, coube a Madalena Braz Teixeira, então diretora do Museu Nacional do Traje, responder àquelas questões no artigo intitulado «Os Museus e as Mulheres em Portugal: Breve História de uma Relação Florescente» (1991, 126-128). Partilhando uma visão otimista sobre o assunto, a autora apresentou, em abono da sua 
opinião, por um lado, o contributo prestado por algumas figuras femininas, sobretudo rainhas ou membros da casa real como é o caso das rainhas D. Leonor, D. Maria I, D. Maria II, D. Leopoldina e a condessa d'Edla, ao longo da história de Portugal, para a formação de coleções ou no apoio mecenático ${ }^{4}$, e, por outro, já no tempo presente, o desempenho de funções diretivas ao nível dos museus, destacando, a esse respeito, o caso singular de Maria José de Mendonça (1903-1983) como conservadora de museus em Portugal durante o período do Estado Novo 5 .

Passados mais de 20 anos sobre a década de 1990 qual é o balanço que se pode fazer sobre esta questão, ao nível internacional e nacional? Será que a relação entre museus e as mulheres continua a ser florescente, tal como a caracterizou Teixeira? Existem museus monográficos, reais ou virtuais, subordinados à temática da mulher e do género? Qual é o seu conteúdo? A museologia de género tem sido posta em prática nos museus? Trata-se de questões a que se irá, na medida do possível, tentar responder.

\section{Museus da mulher e de género: aproximação quantitativa e qualitativa no plano internacional}

11 Se tomarmos por fonte informativa as listas de museus de mulheres e de género que integram a rede internacional Womeninmuseum: The Network of Women's Museums, criada em 2008, no âmbito do 1. Congresso de Museus da Mulher ${ }^{6}$, realizado em Merano (Itália), e aqueles que constam do site Museos de la Mujer. Patrimonio Feminino, sediado no Ministério da Educação, Cultura e Desporto de Espanha ${ }^{7}$, verifica-se que, ao nível mundial, estes são em escasso número (71), sem comparação com outras áreas (quadro n.ํㅜ).

Quadro n. ${ }^{\circ} 1$ - Museus da mulher ou de género no mundo (por ordem decrescente)

\begin{tabular}{|l|l|l|}
\hline Continente & № & $\%$ \\
\hline Europa & 32 & 45,1 \\
\hline América & 23 & 32,4 \\
\hline Ásia & 7 & 9,9 \\
\hline África & 7 & 9,9 \\
\hline Oceânia & 2 & 2,8 \\
\hline Total & 71 & 100 \\
\hline
\end{tabular}

12 Localizam-se sobretudo na Europa e na América (mais de $75 \%$ ), sendo pouco representativos nos restantes continentes. Em termos de países, o maior número de 
museus das mulheres e de género está situado nos EUA e na Alemanha, respetivamente com 14 e seis cada um (quadro $n .{ }^{\circ}$ 2). Quanto a Portugal, não existe qualquer museu desta tipologia.

Quadro n. ${ }^{2}$ - Museus da mulher e do género por país (em número de casos)

\begin{tabular}{|c|c|}
\hline País & № \\
\hline EUA & 14 \\
\hline Alemanha & 6 \\
\hline Espanha & 4 \\
\hline Áustria & 3 \\
\hline Holanda & 3 \\
\hline México & 3 \\
\hline Austrália & 2 \\
\hline Canadá & 2 \\
\hline França & 3 \\
\hline Itália & 2 \\
\hline Vietname & 2 \\
\hline África do Sul & 1 \\
\hline Albânia & 1 \\
\hline Argentina & 1 \\
\hline Bélgica & 1 \\
\hline
\end{tabular}




\begin{tabular}{|c|c|}
\hline Chile & 1 \\
\hline China & 1 \\
\hline Coreia & 1 \\
\hline Costa do Marfim & 1 \\
\hline Costa Rica & 1 \\
\hline Dinamarca & 1 \\
\hline Gâmbia & 1 \\
\hline Índia & 1 \\
\hline Irão & 1 \\
\hline Israel & 1 \\
\hline Japão & 1 \\
\hline Mali & 1 \\
\hline Noruega & 1 \\
\hline Peru & 1 \\
\hline Polónia & 1 \\
\hline República Centro-Africana & 1 \\
\hline Roménia & 1 \\
\hline Senegal & 1 \\
\hline
\end{tabular}




\begin{tabular}{|l|l|}
\hline Sudão & 1 \\
\hline Suécia & 1 \\
\hline Suíça & 1 \\
\hline Turquia & 1 \\
\hline Ucrânia & 1 \\
\hline
\end{tabular}

Em rigor, o primeiro museu da mulher de que se tem conhecimento nasceu na cidade de Bona, na Alemanha, no ano de 1981, tendo resultado de uma ação de ocupação de um edifício levada a cabo por elementos do movimento feminista alemão, sendo considerado, na atualidade, um dos principais museus daquela cidade. É, sobretudo, nos anos 1990, que tem lugar o boom fundacional de museus monográficos dedicados a temáticas femininas (Mirkin 2011), processo que continua em expansão, tendo sido aberto ao público, no final de 2012, um dos últimos museus sobre esta temática: o Museu da Mulher de Haifa, em Israel $^{8}$. Já o único museu que se reivindica exclusivamente de história de género localizase na cidade ucraniana de Kharkiv, tendo sido inaugurado no ano de 2008: trata-se do Museu da História do Movimento Feminista e de Género'. De um modo geral, a abertura deste tipo de museus suscita resistências por parte das instituições oficiais. Em alguns casos, o tempo que medeia entre a proposta da sua criação e a efetiva abertura ao público prolonga-se por períodos superiores a dez anos, como é o caso, entre outros, do Museo de la Mujer da Argentina, sediado em Buenos Aires, o qual foi inaugurado no ano de 2006, 17 anos após a proposta da sua criação, em 1989.

Em termos de caracterização tipológica, a maior parte dos museus (cerca de $62 \%$, quadro n.ํ) 3) são de história e destacam como missão e eixos estratégicos determinadas linhas comuns: contribuir para a reescrita da história do respetivo país, região ou estado, incorporando a dimensão de género, assim como dar visibilidade ao protagonismo feminino nos vários campos da atividade social e cultural.

Quadro n. ${ }^{\circ} 3$ - Tipologia dos museus da mulher e do género (em número de casos)

\begin{tabular}{|l|c|l|}
\hline TIPOLOGIA & № & $\%$ \\
\hline História & 23 & 32,4 \\
\hline História/Direitos das Mulheres & 14 & 19,7 \\
\hline História/Arte & 7 & 9,9 \\
\hline
\end{tabular}




\begin{tabular}{|l|l|l|}
\hline Arte & 13 & 18,3 \\
\hline Direitos das Mulheres & 6 & 8,5 \\
\hline Generalista & 1 & 1,4 \\
\hline Sem informação & 7 & 9,9 \\
\hline TOTAL & 71 & 100 \\
\hline
\end{tabular}

«Lutar contra o esquecimento» e «dar a conhecer as realizações femininas e o papel das mulheres na sociedade» são frases reiteradamente repetidas nos planos de missão destes museus, constituindo o resgate de informação e a reescrita das narrativas do passado um denominador comum e um traço identitário, cuja especificidade é condicionada pelos distintos contextos geográficos e históricos. Esses parâmetros determinam a periodização coberta pelos museus, a qual incide, fundamentalmente, nos séculos XIX e XX, por se tratarem da época charneira do ativismo feminino, seja nos movimentos em prol da obtenção de direitos das mulheres, seja em outro tipo de ações coletivas como os movimentos abolicionistas.

Integram-se nesta tipologia vários museus americanos, tanto dos EUA, do Canadá, como da América Latina. No primeiro caso, enfatiza-se, a nível nacional ou local, a conquista de direitos, sociais e políticos ${ }^{10}$, e o pioneirismo feminino em vários campos, inclusive na aviação e na aeronáutica ${ }^{11}$, mas com particular incidência nos momentos fundadores do feminismo e do sufragismo ${ }^{12}$. Já os museus da América Latina valorizam, sobretudo, o ativismo feminino em favor da independência das novas nações. Destaca-se, ainda, o caso de um museu na República Popular da China, no campo universitário de Changan, em Shaanxi, que releva o papel feminino na luta contra o enfaixamento dos pés (Women Culture Museum). Corolário do discurso que visa denunciar a opressão do género feminino através da história é a glorificação das mulheres que ganharam protagonismo no imaginário social, criando-se «galerias» de mulheres ilustres em todos estes museus. Alguns destes museus estão associados a movimentos feministas, sendo a sua missão orientada para a sociedade contemporânea, obedecendo a uma estratégia de intervenção social e de construção de um futuro menos discriminado, partindo-se do pressuposto que o reforço da imagem das mulheres nos museus aumenta a sua visibilidade política.

Uma outra vertente destes museus, sem marginalizar a questão da obtenção de direitos, incide sobretudo em aspetos da vida privada e quotidiana (trabalho, família, tempos de guerra, corpo e nascimento, entre outros), incluindo temáticas ligadas à evolução histórica da moda e dos ornamentos femininos. Integram-se nesta linha os museus da mulher da Dinamarca e da Noruega, ou, no caso específico da moda, o Expomuseu dos ornamentos da mulher da Alta-Sabóia ou o Museo della Done de Merano. Neste último aborda-se, pela via da moda, a evolução da condição feminina ao longo do tempo.

18 A colaboração estreita com historiadores é uma das traves-mestras de alguns destes museus, com impacto na dinamização de projetos de investigação, na organização de 
exposições e de museus virtuais. Entre outros casos que se poderiam referir, salientam-se o projeto intitulado «Libertadoras», fruto de uma parceria do Museo de la Mujer da Argentina com o Departamento de Estudos Espanhóis, Portugueses e Latino-Americanos da Universidade de Nottingham (Reino Unido) ${ }^{13}$ e a exposição virtual Patrimonio en Femenino ${ }^{14}$, organizada pela Direção Geral de Belas-Artes e Bens Culturais de Espanha em parceria com o Instituto de Investigações Feministas da Universidade Complutense de Madrid. Convém também mencionar o museu virtual Musea, criado pelos departamentos de História e de Tecnologias da Informação e da Comunicação da Universidade de Angers e da Universidade Virtual en Pays de la Loire (França). Através da reprodução digital de obras, de objetos e de testemunhos, bem como de extratos sonoros e de vídeos, procura-se mostrar o contributo feminino em vários campos da atividade, com relevo para a história do feminismo. 0 seu dinamismo apoia-se, em grande parte, no trabalho desenvolvido por duas associações da área de história: Archives du Feminisme, a qual tem como prioridade a recolha documental e o estudo dos movimentos feministas, bem como a associação Mnémosyne (Association pour le Développement de l'Histoire des Femmes et du Genre) (Associations 2003, 266-267). Não surpreende, por conseguinte, a participação de reputadas historiadoras da área dos estudos das mulheres e de género nas comissões científicas deste tipo de museus, como é o caso, entre outras, de Karen offen, docente da Universidade de Stanford e consultora do International Museum of Women, de São Francisco (EUA), ou de Christine Bard, fundadora e dinamizadora do museu virtual Musea ${ }^{15}$.

Os museus identificados como sendo de «direitos das mulheres» têm como missão principal contribuir ou dar testemunho de iniciativas recentes, sobretudo de responsabilidade social envolvendo o sexo feminino. $O$ diálogo entre gerações, grupos étnicos ou religiosos, ou inclusive o combate à violência sexual constituem linhas de força desta tipologia de museus, as quais se refletem nas exposições permanentes ou temporárias. Como exemplos representativos podem-se mencionar o International Museum of Women, em São Francisco (EUA), o Womens' Museum, em Istambul (Turquia) ou, para o caso da temática da violência sobre as mulheres, o Women's Active Museum on War and Peace, no Japão, focado na violência contra as mulheres na Primeira e na Segunda Grandes Guerras.

20 Já os museus de arte visam dar visibilidade à criação artística feminina, preservar o património constituído no campo das artes visuais e assegurar a sua exposição. A este nível convém associar um grupo artístico - as Guerrilla Girls - mulheres com máscara de gorila que, através do humor e da arte (cartazes, performances...), denunciam, entre outras situações, a discriminação de género no universo artístico, incluindo museus ${ }^{16}$. A sua energia criativa tem ajudado a reescrever a história da arte, sob o prisma do feminino e a combater estereótipos.

21 Os museus de arte constituem uma categoria de museu que recorre largamente às novas tecnologias multimédia e à linguagem audiovisual não apenas como meios auxiliares da comunicação expositiva, mas também como instrumentos simbólicos. A desmaterialização feita pelos audiovisuais pretende ser uma metáfora dos vestígios e das fontes para a história das mulheres, sempre ténues e difíceis de recuperar, ao mesmo tempo que a justaposição de obras de arte contemporâneas com outras de épocas anteriores visa significar que as histórias que se narram não pertencem exclusivamente ao passado e que se podem conjugar no tempo presente (Mirkin 2011). 
22 Aliás, de um modo geral, o simbolismo e a metáfora têm, nos museus da mulher, um lugar cativo, seja no discurso expositivo, seja nos edifícios, sendo frequente a recuperação de instalações associadas, de um modo geral, a indizíveis sofrimentos, como prisões, asilos e conventos. Já na criação de cenografias joga-se com a articulação entre os espaços carcerais, a disciplinarização e o controlo do corpo feminino ao longo do tempo. Ainda no âmbito dos museus de arte, se incluem as casas-museu de artistas, sendo uma das mais conhecidas a da pintora Frida Kahlo, na cidade do México ${ }^{17}$.

Quanto às exposições temporárias que se reivindicam inspiradas na museologia de género constituem um fenómeno relativamente recente e não são muito frequentes, tendo, sobretudo, lugar em museus da mulher ou em museus internacionais de arte contemporânea. Nas restantes categorias de museus, são escassas as exibições que visam interpretar os quotidianos femininos ou que veiculam problemáticas de género ${ }^{18}$. No nosso país são, no entanto, em fraco número as exposições que se integram nesta qualificação, e, entre aquelas que é possível elencar, a partir de informações online, salientam-se duas exposições realizadas no Museu Francisco Tavares Proença Júnior, em Castelo Branco, no ano de 2011, e comissariadas por Aida Rechena ${ }^{19}$ : Museu no Feminino (1): Mulheres Artistas na Coleção do Museu e Museu no Feminino (2): as Mulheres no Olhar dos Homens . Estas exposições constituíram dois dos estudos de caso analisados por esta museóloga na sua dissertação de doutoramento intitulada Sociomuseologia e Género: Imagens da Mulher em Exposições de Museus Portugueses (Rechena 2011a), com a qual receberia o Prémio APOM (Associação Portuguesa de Museologia) 2012, na categoria do melhor estudo sobre museologia.

De um modo geral, alguns autores propõem, em termos teóricos e epistemológicos, como caminhos possíveis para a integração da museologia de género nas exposições temporárias, a escolha de temas sobre questões de género, bem como alterações da museografia e da linguagem do discurso expositivo (Pollock 2007; Lévin 2010). A fim de se estabelecer o protagonismo feminino nos museus, sugere-se, entre outras vias, dar visibilidade à mulher artista, às colecionadoras, às mecenas, às curadoras, às museólogas ${ }^{20}$ , às trabalhadoras em geral (auxiliares, administrativas, técnicas de restauro, etc.) ${ }^{21}$, bem como às voluntárias que prestam serviços em museus (visitas guiadas, apoio de conferências ou ateliers e workshops) (Peyrin 2008, 65-85) ${ }^{22}$.

Não se dispõe de muitos estudos sobre a evolução do pessoal técnico dos museus ao longo do tempo. Segundo a historiadora Peyrin, foi pela via do voluntariado feminino que as mulheres começaram a ingressar nos museus americanos e franceses no início do século XX. Na opinião desta autora, o voluntariado inscreve-se na definição que Perrot dá de «trabalho feminino», ao enquadrá-lo no prolongamento das «funções naturais da mulher», maternais e domésticas $(1987,3-8)^{23}$.

26 Já o colecionismo feminino tem raízes antigas, remontando, pelo menos nos países ibéricos, ao século XV. Bolaños Atienza, reportando-se ao caso espanhol, qualifica a colecionadora-tipo dos tempos mais recuados de doméstica, herdeira de legados e agindo por dever familiar (2011, 36-41). A formação de coleções por mulheres é mais tardia, sendo, sobretudo, um fenómeno da época contemporânea (séculos XIX e XX) ${ }^{24}$. O colecionismo integra-se na lógica das classes médias, no culto do lar e do conforto, aspetos significativos da importância assumida pela vida privada no século de oitocentos (Vaquinhas 2011b, 454-464). Indo ao arrepio de uma ideia convencional de que o homem é colecionador e a mulher consumidora, numerosos autores têm equacionado, nos últimos tempos, em novos moldes, o colecionismo feminino e a cultura material associada às 
mulheres. Os trabalhos feitos à mão ${ }^{25}$, os «mil e um pequenos nadas», por vezes, tão ironizados, seja por motivos financeiros, seja por simples entretenimento, foram, em numerosos casos, embriões de coleções que, como afirma Edwards, foram «literalmente criadas» $(2008,50)$. A própria noção de conforto exigia, ao tempo, a acumulação de peças (o gosto pelo bric-à-brac de que falam alguns autores), entre os quais, porcelanas, obras de arte, livros, ou outros objetos que favoreciam a constituição de coleções e de verdadeiros «museus interiores» (Corbin 1990, 496-501), para os quais as mulheres parecem ter tido uma intervenção maior do que se supunha.

Muitos outros aspetos poderiam ser explorados. Porém, sob o ponto de vista da museologia de género, o que se pretende é recuperar a voz e o labor femininos dentro dos museus, desconstruir os discursos e convertê-los em mote de exposições, de maneira a que não se perpetue o silenciamento das mulheres.

\section{Conclusão}

Vá ao museu mais perto de si e conte os trabalhos assinados por mulheres... O desafio lançado pelas Guerrilla Girls há alguns anos mantém-se atual: como caracteriza a museóloga Bolaños Atienza, a relação das mulheres com os museus define-se pela ausência (2011, 36-41), sobretudo ao nível dos discursos expositivos, se bem que, quanto aos corpos técnicos e profissionais, se tenham registado alterações significativas.

Porém, sendo os museus lugares de memória, importa introduzir pontos de vista tendentes à igualdade, de modo a que também reflitam o protagonismo feminino no processo da construção humana. $\mathrm{O}$ arquétipo dos grandes museus da Europa ocidental (Museu Britânico, Louvre, Pergamon...) e que haveriam de conformar a sociedade moderna, refletem pontos de vista, no dizer de López Cao, «profundamente androcêntricos» $(2011,78)$. Tendo constituído elementos fundamentais na formação dos nacionalismos e dos colonialismos (Levin 2010, 1-2), exibindo os espólios da conquistas e os pontos de vista dos vencedores, subentendem um discurso de género que valoriza a masculinidade e as funções militares, associando a mulher à vida privada e à maternidade. Fundamentado em princípios darwinistas, o discurso ideológico que veiculam pressupõe hierarquias entre as raças, entre as nações e entre os sexos (Caine e Sluga 2000, 111-122), que se traduzem em narrativas que marginalizam as mulheres. A introdução do conceito de género no vocabulário corrente dos feminismos nos anos 1960 veio imprimir a várias ciências humanas e sociais uma profunda renovação. Ao pôr em causa o determinismo biológico, obrigou a questionar a construção social das diferenças sexuais e as suas consequências nas partilhas do poder, na influência política e no diferente acesso aos recursos económicos, bem como o seu impacto na produção do conhecimento científico e tecnológico. Nos anos 1980-1990, o conceito de género, enquanto construto social, entrou na linguagem museológica, afetando positivamente os discursos expositivos de alguns museus ou fazendo emergir uma nova tipologia de museus. Estes enquadram-se num processo mais vasto de reabilitação do feminino e têm desempenhado um papel importante não apenas no próprio desenvolvimento geral dos temas históricos mas também na formação da consciência feminista, contribuindo para uma mais larga compreensão da desigualdade dos sexos. Na atualidade, os museus da mulher e/ou do género estão a abrir novos caminhos tanto no campo especificamente historiográfico como no levantamento de problemáticas que ajudam a compreender o modo como as mulheres modelaram as suas vidas e as articularam (e articulam) com as 
mudanças sociais. Enfim, a frase de um anúncio publicitário dos anos 1940 de que «só as mulheres pintadas sejam próprias de museus» pertence definitivamente ao passado...

\section{BIBLIOGRAFIA}

Arjona Cano, Rosa María. 2011. “Las Mujeres como Personal de Museos.” In Patrimonio en Femenino , 83-86. Madrid: Ministerio de la Cultura. http://www.calameo.com/read/0000753353fdf029c796c.

Associations; Sites internet. 2003. Clio. Histoire, Femmes et Sociétés 18: 266-269.

Bard, Christine. 2002. “Les Musées des Femmes à l'Étranger." Bulletin Archives du Féminisme 3 (Janvier). http://www.archivesdufeminisme.fr/article.php3?id_article=24.

Bolaños Atienza, 2011. “Las Mujeres en los Museos: Entre Museólogas y Colecionistas.” In Patrimonio en Femenino, 36-41. Madrid: Ministerio de la Cultura. http://www.mcu.es/museos/MC/ PatrimonioFemenino/.

Borrêcho, Maria do Céu de Brito Varinho. 2005. "Julieta Bárbara Ferrão". In Dicionário no Feminino (séculos XIX e XX), direção de Zília Osório de Castro, e João Esteves, 489-490. Lisboa: Livros Horizonte.

Caine, Barbara, e Glenda Sluga. 2000. Género e Historia: Mujeres en el Cambio Sociocultural Europeo, de 1780 a 1920. Madrid: Narcea.

Corbin, Alain. 1990. “O Segredo do Indivíduo.” In História da Vida Privada: Da Revolução à Grande Guerra. Vol. 4. Direção de Philippe Ariès, e Georges Duby, 419-501. Lisboa: Círculo de Leitores.

Duarte, Adelaide. 2012. "Da Coleção ao Museu. O Colecionismo Privado de Arte Moderna e Contemporânea em Portugal, na Segunda Metade do Século XX. Contributos para a História da Museologia." Tese de Doutoramento em Letras, área de História e especialidade em Museologia e Património Cultural, Faculdade de Letras, Universidade de Coimbra.

Edwards, Clive. 2008. "Women's Home-Crafted Objects as Collections of Culture and Comfort, 1750-1900." In Material Cultures 1740-1920: The Meanings and Pleasures of Collecting, editado por John Potvin, e Alla Myzelev, 37-52. Farnham: Ashgate.

Goggin, Maureen Daly, e Beth Fowkes Tobin, eds. 2009. Material Women, 1750-1950: Consuming Desires and Collecting Practices. Farnham: Ashgate.

Goggin, Maureen Daly, e Beth Fowkes Tobin, eds. 2009. Women and Things, 1750-1950: Gendered Material Strategies. Farnham: Ashgate.

Greenberg, Reena. 1992. “Dedans/Dehors: Les Musées, les Femmes et la Fausse Publicité.” Musée 14 (1): 22-24. http://www.yorku.ca/reerden/Publications/DEDANS/dedans_dehors.html.

Guerrilla Girls. 2012. The Guerrilla Girls' Art Museum Activity Book. [n. p.]: Printed Matter, Inc.

Lévin, Amy K. 2010. “Introduction.” In Gender, Sexuality, and Museums: a Routledge Reader, 1-2. New York: Routledge. 
López Cao, Marián Fernández. 2011. “Es Necesario un Museo de Mujeres?” In Patrimonio en Femenino, 77-81. Madrid: Ministerio de la Cultura. http://www.mcu.es/museos/MC/

PatrimonioFemenino/.

Matsushita, Tomoko. 1991. “Au Japon: Les Benévoles du Musée Nationale des Sciences.” Museum International, Les Musées au Féminin 43 (3): 144.

Mirkin, Dina Comisarenco. 2011. "Resignificando Espacios: los Museos de la Mujer en México y Argentina." http://www.museodemujeres.com/es/biblioteca/35-resignificando-espacios-losmuseos-de-la-mujer-en-mexico-y-argentina.

Nash, Mary. 2005. As Mulheres no Mundo: História, Desafios e Movimentos. Vila Nova de Gaia: Editora Ausência.

Perrot, Michelle. 1987. “Qu'est-ce qu'un métier de femme?” Le Mouvement Social 140 (JuilletSeptembre): 3-8.

Peyrin, Aurélie. 2008. “Démocratiser les Musées: Une Profession Intellectuelle au Feminine.” In Travail, Genre et Sociétés 1 (19): 65-85.

Pinto, Renato. 2012. "Museus e Diversidade Sexual: Reflexões sobre Mostras LGBT e Queer." Arqueologia Pública 5. http://www.nepam.unicamp.br/arqueologiapublica/artigos/artigo4_5.pdf. Pollock, Griselda. 2007. Encounters in the Virtual Feminist Museum: Time, Space and Archive. London e New York: Routledge.

Porter, Gaby. 1991. "Comment les Femmes Sont-elles Représentées dans les Musées d'Histoire Britanniques?” Museum International, Les Musées au Féminin 43 (3): 159-162.

Portes, Élisabeth des, e Raffin, Anne. 1991. “Les Femmes à l’ICOM.” Museum International, Les Musées au Feminin 43 (3): 129-132.

Potvin, John, e Alla Myzelev, eds. 2008. Material Cultures 1740-1920: The Meanings and Pleasures of Collecting. Farnham: Ashgate.

Rechena, Aida. 2011a. "Sociomuseologia e Género: Imagens da Mulher em Exposições de Museus Portugueses." Tese de doutoramento em Museologia, Universidade Lusófona de Humanidades e Tecnologias. http://www.museologia-portugal.net/files/upload/doutoramentos/ aida_rechena.pdf.

Rechena, Aida. 2011b. “Teoria as Representações Sociais: Uma Ferramenta para a Análise de Exposições Museológicas.” Cadernos de Sociomuseologia 41: 211-244.

Rodriguez, Andréia da Fonseca. 2010. "Gênero no Espaço do Museu: uma Leitura Social da Exposição ‘Entre Rendas, Chapéus e Boas Maneiras', Museu Municipal Parque da Baronesa, Pelotas/RS." Monografia em Museologia, Universidade Federal de Pelotas. http:// museologiaufpel.files.wordpress.com/2010/09/andreia.pdf.

Rose, Vivien Ellen. 2001. “Le Parc Historique National des Droits de la Femme: Òu les 'Droits' sont Notre Mission.” In Museum International, Les Musées d'Histoire Sociale 53 (209): 32-36.

Skjoth, Lise. 1991. "Introduction de la Ccordonnatrice du Présent Número: Un inédit. Museum International, Les Musées au Féminin 43 (3): 124-125.

Szperling, Cecilia. 2010. “Encuentro de Museos de Mujeres.” Clarin.com. http://www.clarin.com/ sociedad/Encuentro-museos-mujeres_0_271772890.html?print=1.

Teixeira, Madalena Braz. 1991. "Les Musées et les Femmes au Portugal: Brève Histoire d'une Relation Florissante." Museum International, Les Musées au Féminin 43 (3): 126-128. 
Vahé, Isabelle. 2009. “Le $2^{\mathrm{e}}$ Congrès des Musées de Femmes, Bonn, 9-11 septembre 2009.” Genre \& Histoire: La Revue de l'Association Mnémosyne 5 (Automne). http://genrehistoire.revues.org/787.

Vaquinhas, Irene. 2005a. As Mulheres no Mundo Contemporâneo: História Comparada. Coimbra: Faculdade de Letras da Universidade de Coimbra.

Vaquinhas, Irene. 2005b. "Linhas de Investigação para a História das Mulheres nos Séculos XIX e XX: Breve Esboço." In Nem Gatas Borralheiras, Nem Bonecas de Luxo: As Mulheres Portuguesas Sob o Olhar da História (Séculos XIX-XX), 125-153. Lisboa: Livros Horizonte.

Vaquinhas, Irene. 2011a. "Estudos sobre as Mulheres a Área de História." In «Senhoras e Mulheres» na Sociedade Portuguesa do Século XIX, 163-184. 2. ed. Lisboa: Edições Colibri.

Vaquinhas, Irene. 2011b. "Em Torno dos Objetos da Vida Privada." In História da Vida Privada em Portugal, A Época Contemporânea, 454-464. Lisboa: Círculo de Leitores.

\section{NOTAS}

1. "Chama-se género à masculinidade ou à feminilidade convencionadas socialmente, em contraste com o sexo que é o termo usado para designar as diferenças biológicas e fisiológicas entre homens e mulheres». O conceito de género é mais abrangente do que a palavra sexo, ou seja, o primeiro é um dado cultural; o segundo um dado biológico. Nos anos 90 , a introdução do conceito de género no discurso historiográfico afetou, de uma forma significativa, a história das mulheres, quer fazendo avançar novas linhas de pesquisa, quer obrigando a reavaliar «as grandes questões da história», conferindo espessura problematizante, partindo-se do pressuposto de que a diferença de sexos não é apenas um fenómeno natural, mas uma construção cultural e histórica (Vaquinhas 2005a, 33-34).

2. Os estudos de género são mais abrangente do que os que incidem especificamente sobre a história das mulheres e podem incidir sobre indivíduos ou grupos de lésbicas, gays e bissexuais, bem como membros de comunidades marginalizadas pelas suas práticas sexuais dissonantes das normas sociais (Pinto 2012). Neste artigo, circunscreve-se a análise à questão feminina.

3. De um modo geral, as áreas educativas dentro dos museus são bastante feminizadas.

4. Seria, no entanto, conveniente distinguir entre coleções constituídas por mulheres e aquelas que resultaram de heranças ou de partilhas, passando-se a dispor de legados para cuja formação o papel feminino foi nulo ou fracamente interventivo.

5. Em rigor, a primeira conservadora de museus, em Portugal, foi Julieta Bárbara Ferrão (1899-1974) que exerceu essa função no quadro dos Museus Municipais de Lisboa e foi diretora do Museu Rafael Bordalo Pinheiro (Borrêcho 2005, 489-490).

6. http://www.womeninmuseum.net/blog/?page_id=2 (consultado abril 22, 2013). A criação da rede de museus da mulher obedeceu às seguintes finalidades: aumentar a visibilidade e a aceitação de museus da mulher; a colaboração entre os vários museus; a partilha de plataformas online como apoio e incentivo do trabalho da rede. Incluíam-se, ainda, nas propostas apresentadas, a filiação no ICOM.

7. www.mcu.es/museos/MC/PatrimonioFemenino/ (consultado abril 4, 2013).

8. http://www.mfa.gov.il/MFA/IsraelExperience/Museum-of-Israeli-women23-October2012 (consultado abril 10, 2013).

9. http://www.grassrootsfeminism.net/cms/node/1194 (consultado abril 10, 2013).

10. Também nos EUA existe o Parque Histórico dos Direitos da Mulher, em Seneca Fall, no Estado de Nova Iorque, marco fundador na história da emancipação feminina. Foi nesta localidade que, no ano de 1848, tiveram início os movimentos de mulheres, tendo-se aí realizado o primeiro congresso feminista que se destinava a analisar a questão das mulheres à luz da Declaração de 
Independência dos Estados Unidos (1776). Desse congresso fundador nasceu a «Declaração dos Sentimentos», na qual se afirmava que «todos os homens e as mulheres nascem iguais» e se reivindicava para o sexo feminino «a obtenção imediata de todos os direitos e privilégios que o sexo masculino tinha, na sua qualidade de cidadão» (Rose 2001, 32-36; Nash 2005, 79-84). Veja-se também: http://www.nps.gov/wori/index.htm (consultado abril 20, 2013). Os museus desta temática do continente americano tendem a destacar o contributo feminino para a história dos respetivos países ou regiões, seja para a história do EUA, ou do Peru, seja para a história do Estado de Alabama ou da região do Quebeque.

11. É o caso do International Women's Air \& Space Museum: http://iwasm.org/wp-blog/ (consultado abril 22, 2013).

12. Refira-se, a título exemplificativo, que uma das primeiras iniciativas do National Womens's History Museum, de Washington, foi a colocação na rotunda do Capitólio de uma estátua comemorativa da obtenção do direito de voto pelas mulheres, dedicada a três sufragistas americanas do início do século XX. Sobre o assunto v. Bard (2002).

13. Museo de la Mujer (Argentina): www.museodelamujer.org.ar/ (consultado abril 10, 2013).

14. Patrimonio en femenino: http://www.mcu.es/novedades/2011/ novedades_patrimonio_femenino.html. (consultado abril 10, 2013). No ano de 2013, o tema da exposição intitulou-se Mujeres Ante la Adversidad: Tiempos y Contratiempos: http:// www.ibermuseus.org/es/noticias-es/patrimonio-en-femenino2/ (consultado abril 10, 2013).

15. http://www.mnemosyne.asso.fr/index.php?page=journee-d-etude2013 (consultado abril 17, 2013).

16. O agrupamento artístico Guerrilla Girls, segundo o site consultado, nasceu nos EUA em reação a uma exposição realizada, no ano de 1985, no Museum of Modern Art de Nova Iorque, na qual se pretendia reunir os artistas mais significativos da arte contemporânea. Dos 169 artistas expostos, apenas 13 (7,7 \%) eram do sexo feminino e todos, sem exceção, eram de raça caucasiana (http:// obviousmag.org/archives/2011/07/

guerrilla_girls_gorilas_justiceiras_no_mundo_da_arte_1.html\#ixzz2RqdH0b3y ). Sobre o assunto veja-se também Guerrilla Girls (2012).

17. La Casa Azul: El Museo de Frida Kahlo: http://www.museofridakahlo.org.mx/ (consultado abril 22, 2013).

18. 0 estudo do tema de exposições sobre mulheres e/ou questões femininas ou de género, a nível mundial, exige um outro tipo de problemáticas e de levantamento de fontes a que não se procedeu no âmbito deste artigo, deixando-se apenas registadas breves considerações.

19. Museu no Feminino (1): Mulheres Artistas na Coleção do Museu: http:// samftpj.blogspot.pt/2011/06/exposicao-museu-no-feminino-mulheres.html (consultado abril 28, 2013).

20. Uma outra possibilidade é a análise da participação feminina nas estruturas dirigentes de instituições museológicas internacionais (Portes e Raffin 1991, 129-132).

21. Nos museus espanhóis estatais, no ano de 2011, as mulheres constituíam 66,4 \% de todo o pessoal trabalhador (Arjona Cano 2011, 83).

22. No Japão, país onde o número de museus é considerável, o corpo de voluntários em museus era, nos anos 1990, maioritariamente constituído por mulheres, sendo muito valorizado (Matsushita 1991, 144).

23. Trata-se de um discurso que subentende qualidades atribuídas a cada sexo, sendo reconhecido ao sexo feminino a gentileza, a destreza de mãos, a paciência e a docilidade, o que determinaria, ao tempo, a separação entre profissões femininas e profissões masculinas.

24. Sobre o colecionismo de arte moderna e contemporânea, onde figuram, ao nível internacional, alguns casos bem conhecidos de colecionadoras, como Peggy Guggenheim, veja-se, entre outra bibliografia, Duarte (2012). 
25. A personalização das peças feitas à mão constitui uma das manifestações da individualidade e da afirmação do eu, características do período do liberalismo. Trata-se também de uma expressão da "cultura material do amor», uma vez que se trata de artefactos fortemente investidos de valores afetivos e com objetivos específicos.

\section{RESUMOS}

Os museus da mulher, criados num determinado contexto sociocultural, são relativamente recentes, datando os primeiros casos de meados dos anos 1980, embora se multipliquem nas décadas posteriores. Neste artigo é feito o levantamento dos principais museus da mulher e/ou género existentes ao nível mundial, assim como é problematizada a relação entre museus e história das mulheres e o conceito recente de museologia de género. Equacionam-se igualmente os principais vetores, as missões e as linhas estratégicas dessa tipologia de museus e abordam-se os principais conteúdos das respetivas exposições permanentes.

Women's museums are a relatively new concept. Founded in a specific sociocultural context, the first dating from the 1980s, and their numbers have continuously increased during the following decades. This article surveys the main women's and/or gender museums at worldwide level and questions the link between museums and the history of women, and the new concept of gender museology. Consideration is also given to the main vectors, tasks and strategic outlines of this typology of museums and the main contents of their permanent exhibitions.

\section{ÍNDICE}

Keywords: women's and gender museums, gender museology, feminine material culture, women history and gender, women history Portugal

Palavras-chave: museus mulher e género, museologia de género, cultura material feminina, história mulheres e género, história mulheres Portugal

\section{AUTOR}

\section{IRENE VAQUINHAS}

Professora catedrática da Faculdade de Letras da Universidade de Coimbra. É coordenadora científica do Centro de História da Sociedade e da Cultura. Destacam-se as seguintes publicações: Violência, Justiça e Sociedade Rural: Os Campos de Coimbra, Montemor-o-Velho e Penacova de 1858 a 1918 (1996); Senhoras e Mulheres na Sociedade Portuguesa do Século XIX (1999); Nome de Código 33856: Os Jogos de Fortuna ou Azar em Portugal entre a Repressão e a Tolerância (De finais do século XIX a 1927) (2006); O Casino da Figueira: Sua Evolução Histórica Desde o Teatro-Circo à Atualidade (1884-1978) (2012). Colaborou no V volume da História de Portugal dirigida por José Mattoso (1993) e coordenou (e colaborou) o III volume da História da Vida Privada em Portugal, A Época Contemporânea (2011). irenemcv@fl.uc.pt 